\title{
VIDEODENSITOMETRIC PROCESSING OF CONTRAST TWO-DIMENSIONAL ECHOCARDIOGRAPHIC DATA $\dagger$
}

\author{
Richard S. Meltzer, $\ddagger$ Jos Roelandt, Olchert L. BastiaAns, \\ Luc Piérard, Patrick W. Serruys and Charles T. Lancée \\ Thoraxcenter, Erasmus University and University Hospital, Rotterdam, The Netherlands and Delft \\ University of Technology, Delft, The Netherlands
}

Key Words: Echocardiography, Ultrasonic contrast, Indicator-dilution curves.

\begin{abstract}
We developed a computer program to analyze videodensity changes due to contrast appearance within a given operator-designated rectangle using two-dimensional echocardiograms previously recorded on videotape. Videodensity curves have been obtained from two-dimensional echocardiographic recordings in 14 patients after a total of 32 injections of $5 \%$ dextrose solution into the left ventricle during cardiac catheterization.

The resulting videodensity vs time curves have some characteristics of indicator-dilution curves. The decay phase of these curves is largely mono-exponential. Potential clinical applications of this technique in measurement of ejection fraction, cardiac output and shunt quantification are discussed, as well as some potential limitations.
\end{abstract}

\section{INTRODUCTION}

Since 1978, the group from Davis, California (Bommer et al. 1978; DeMaria et al. 1978; Bommer et al. 1979 and DeMaria et al. 1980) has presented several abstracts describing methods for obtaining curves with properties similar to indicator-dilution curves by using videodensitometric analysis of videotaped two-dimensional echocardiographic studies recorded during peripheral contrast injections. Investigators from the Mayo Clinic (Hagler and Tajik, 1978) have presented preliminary data on videodensitometric studies for the quantitation of left-to-right shunts during left heart echocardiographic contrast injections.

In this report we examine the possibility and discuss some of the advantages and disadvantages of using videodensity data for obtaining "indicator-dilution curves".

\section{PATIENTS AND METHODS}

Videotaped two-dimensional echocardiographic studies of contrast injections recorded in the catheterization laboratory during two prior research protocols (Bastiaans et al. 1981 and Meltzer et al. 1980a)were used for analysis. Twelve patients had manual in-

$†$ This work was supported in part by a Clinician Scientist Award to Dr. Meltzer from the American Heart Association and in part by a grant to Mr. Bastiaans from the Dutch Heart Association.

$\ddagger$ Please address correspondence to: Richard S. Meltzer, M.D., Cardiology Division, Mt. Sinai Medical Center, One Gustave Levy Place, New York, NY 10029, U.S.A. jections of $10 \mathrm{ml}$ of $5 \%$ dextrose in water directly into the left ventricle (6) and 5 patients had manual injections of $5 \%$ dextrose in water into the pulmonary wedge position. All patients were studied during catheterization for routine clinical indications. The two-dimensional echocardiograms and contrast injections added only 5-15 min to the total duration of the procedure. There were no adverse effects. All patients having pulmonary wedge injections and 9 of the 12 patients with direct left ventricular injections were judged during review of the videotapes to have sufficient contrast density in the left ventricle to allow videodensitometric analysis.

\section{Echocardiographic analysis}

Echocardiograms were recorded in the supine or shallow left lateral decubitus position. All studies were performed in the apical four-chamber view (Meltzer et al. 1980b). A Toshiba SSH-10A phased array sector scanner was employed, and studies were recorded on videotape for subsequent analysis.

The hardware configuration for data analysis is diagrammed in Fig. 1. A videorecorder capable of display in real time, slowmotion or stop-frame modes is connected to a PDP-11 minicomputer. The operator can interact with the system by means of a Summagraphics digitizing tablet-light pen system. After viewing and reviewing the recording of an echo contrast injection, the operator can tentatively designate a rectangular area for analysis (Figs. 2 and 3). He then views the 


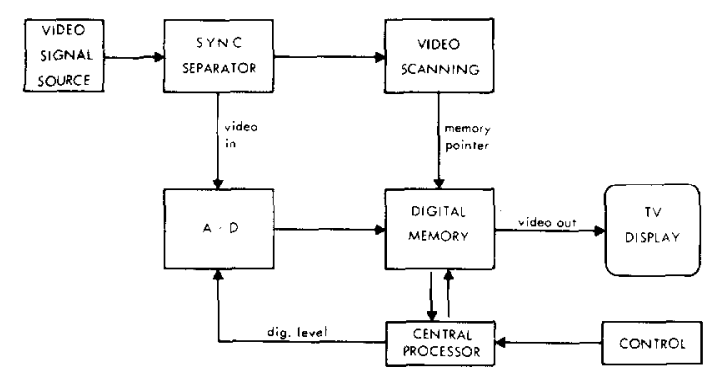

Fig. 1. Hardware configuration for data analysis. The video synch signal is obtained from a video signal source (usually videotape) and the image is entered into a digital memory after analog/digital (A/D) conversion. The operator can interact (CONTROL) with the central processor (in this case a PDP 11 minicomputer) and the resulting superimposed original video image and superimposed alphanumeric information are displayed on the monitoring TV screen.

entire study, from the initial contrast appearance to its complete disappearance, to verify that the boundaries of the selected area remain entirely within the ventricular cavity where contrast dynamics are to be assessed. If the cavity wall (usually at endsystole) or other anatomic structures (such as a valve) enter the area during the cardiac cycle the boundaries of the rectangle are readjusted so the structure remains outside the tentative test area. When this process is completed the study is rewound to a point just prior to contrast appearance and the videodensity program is started. It calculates the total videodensity of all pixels within the designated test area for each subsequent

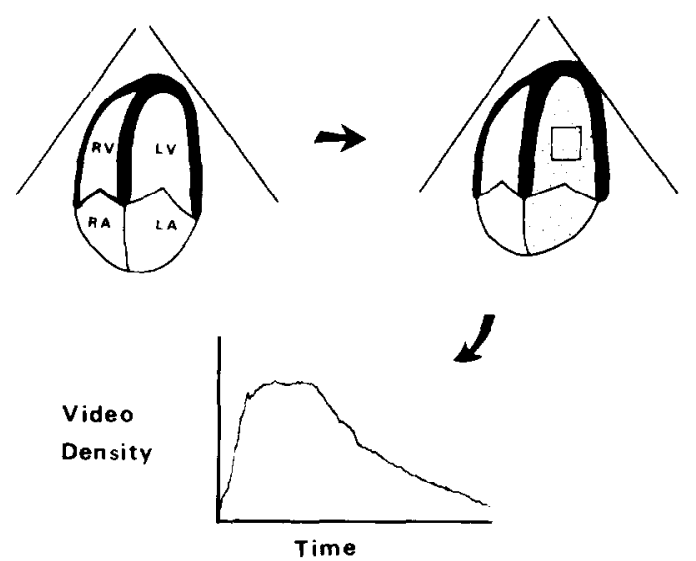

Fig. 2. Principle of videodensity analysis. Upper panels: Two-dimensional echocardiographic data is videotaped during a contrast injection, depicted here by stippling in the left atrium (LA) and left ventricle (LV) after peripheral venous injection. Upper right: After review, the operator designates a rectangular area for analysis. Lower panel: The program output is in the form of total videodensity within the designated rectangle vs time. frame chosen by the operator. The program allows an operator to obtain videodensity measurements for each frame, every other frame, every $n$th frame, etc.

\section{RESULTS}

Videodensity curves could be obtained in all cases where prior real-time viewing revealed a cavity size about $2 \times 2 \mathrm{~cm}$ or greater, and "moderate" to "intense" contrast. An example of such a curve is given in Fig. 4.

To test whether the latter part of these curves was a mono-exponential decay as would be expected from one-compartment indicator-dilution theory (Bloomfield 1974), we plotted $\log$ videodensity vs time. Figure 5 presents the resulting plot for the curve illustrated in Fig. 4. In this patient the decay phase has a log videodensity closely correlated with time (correlation coefficient $r=$ 0.98 ), which implies that the decay fits a mono-exponential model, as predicted. Small cyclic deviations from linearity may be expected due to the incoming contrast free blood during each diastole, unless the videodensity readings are performed only once per cycle, from a frame at the same point in each cardiac cycle.

Of the 32 injections in 14 patients, 15 injections in 10 patients had correlation coefficients between log videodensity during decay and time that were greater than or equal to 0.95 . The slope of this semilog decay plot should be one of the most important parameters obtainable from this technique: it is the time constant of contrast disappearance. We therefore undertook to examine a single good quality injection to determine for what duration its decay needed to be sampled to obtain reliable information about this slope. We arbitrarily defined a "reliable" slope as that obtained from at least 5 separate videodensity determinations during decay, yielding a semilog correlation coefficient of greater than or equal to 0.95 . Figure 6 is the result. On the abscissa is the duration of the segment randomly chosen during the decay phase and then analyzed for videodensity every fifth frame. On the ordinate is the linear correlation coefficient obtained in the resulting log videodensity vs time plot. The shape of this curve is to be expected: a wider range (longer time of sampling, on the abscissa) yields a better correlation coefficient. The important result is 


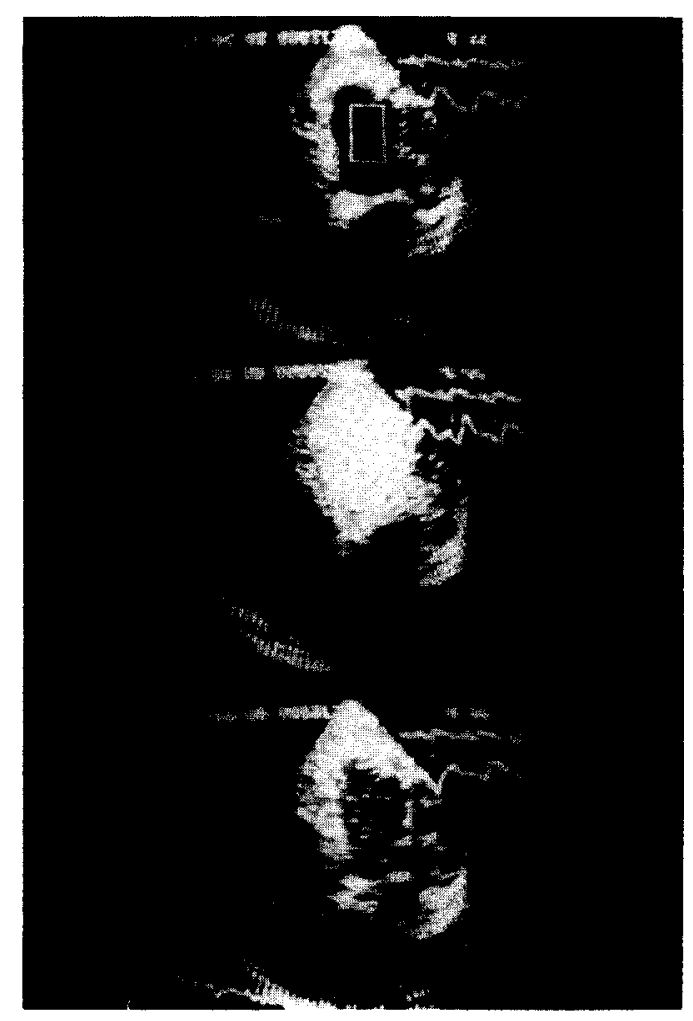

Fig. 3. Upper panel: A rectangular sample area has been designated within the left ventricle. Apical four-chamber view. This frame is immediately prior to contrast opacification after a catheter left ventricular injection. Middle panel: The outline of the sample area is seen faintly during maximal contrast intensity. Note simultaneous display of cumulated videodensity at lower left of panel. Lower panel: The left ventricular contrast has nearly been cleared. 


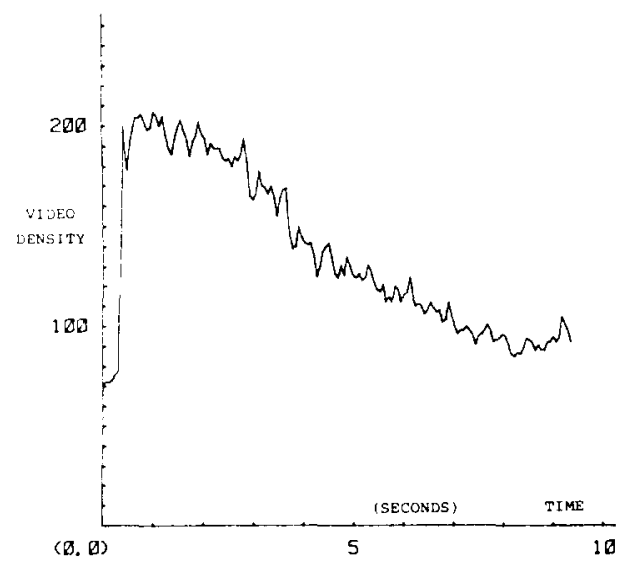

Fig. 4. Sample videodensity vs time curve obtained from left ventricular injection. Videodensity in arbitrary units.

that when performing videodensity analysis every fifth frame, about $5 \mathrm{sec}$ of decay need to be entered to yield the best correlation coefficient. In this specific injection, longer analysis is unnecessary.

\section{DISCUSSION}

Videodensity techniques for indicator-dilution analysis

The most important finding in this study is that videodensity vs time curves can indeed be obtained from most left ventricular injections in the majority of patients, and that these seem to have the qualitative shape we expect of a one-compartment indicator-dilution curve, as well as the quantitative characteristic of a mono-exponential decay. The set of contrast injections we used (LV or wedge) has two known advantages for this

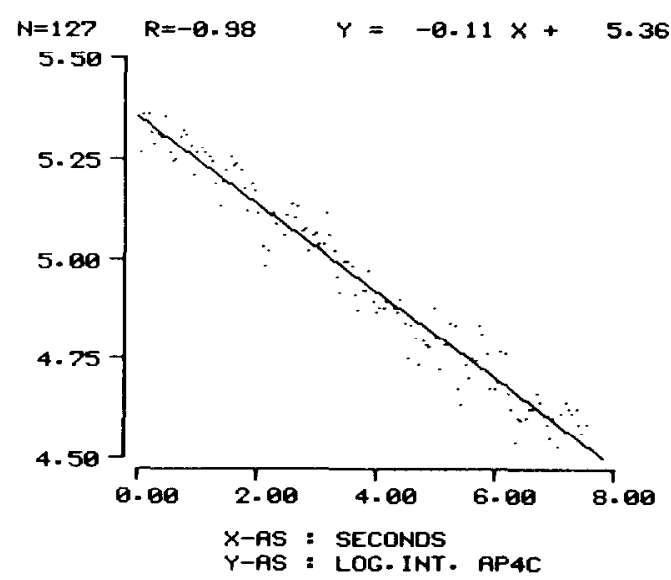

Fig. 5. Log videodensity (on ordinate) vs time curve for the decay phase of the videodensity-vs-time curve shown in Fig. 4. type of analysis: a rapid and complete delivery of the injected bolus into the chamber to be studied (by direct catheter injection) and a relatively large cross sectional surface area on two-dimensional echocardiography (the LV in the apical 4-chamber view). Whether a similar success rate can be obtained with peripheral venous injection and right ventricular imaging is uncertain.

\section{Advantages}

An advantage of right-sided videodensity analysis is that it is minimally invasive, needing only an intravenous injection and the same two-dimensional echocardiographic equipment and videorecorder available in many or most cardiology divisions. Rudimentary curves can even be obtained in real time using an inexpensive photoelectric cell. Theoretically, videodensity curves may be used to quantify right and left ventricular ejection fractions, intracardiac shunts, and cardiac output (if no "overload" occurs-see below).

\section{Limitations}

Echocardiographic contrast injections are not reproducible: the microbubbles size and concentration reaching the central circulation and resulting ultrasonic contrast effect vary widely, even on consecutive injections with apparently identical technique. This problem may be partly surmountable if precision microbubbles are used as the contrast agent (Bommer et al. 1979; DeMaria et al. 1980 and Meltzer et al. 1980c). However, it is possible that even precision microbubbles injected

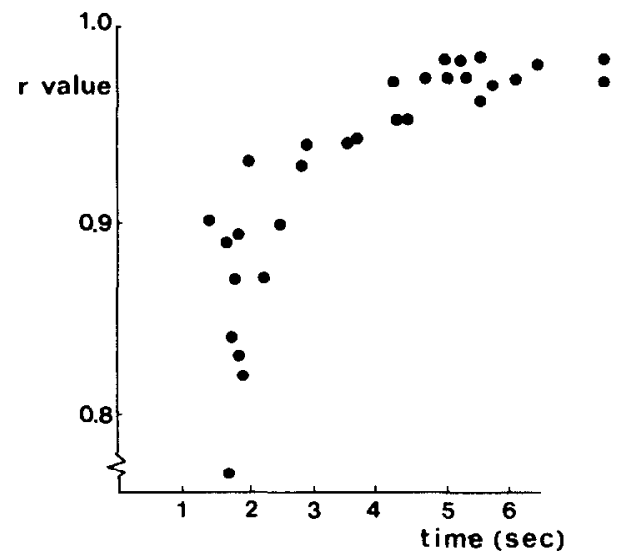

Fig. 6. Correlation coefficient between log videodensity and the duration of decay measured for different randomly chosen durations (time) during the decay of a single curve. For this curve, it would seem unnecessary to measure more than $5 \mathrm{sec}$ of decay. 
peripherally will result in very variable cardiac videodensity curves. Some patients have rapid delivery of a peripherally injected bolus into the right heart, and others have an intermittent delivery over many minutes, with oscillations of contrast intensity in the absence of new injections, frequently caused by arm or head motion or deep inspiration.

Compared to the dynamic range of ultrasonic signals returning to the transducer, the gray-scale capabilities of the cathode ray tube display offer a very restricted range. This is further complicated by signal degradation during the videoprocessing and recording in most commercially available systems. The initial system designed to process two-dimensional echocardiographic recordings to yield videodensity curves was reported in 1978. It used a hand-held photoelectric cell applied directly to the cathode ray tube screen (Bommer et al. 1978). Theoretically, more information can be obtained by direct analysis of the pre-processed signal of the returning echoes, eliminating the need for an intermediary video step with its attendant loss of information.

There are 2 different types of "overload" effects that may limit the peak density observed during a contrast injection. Above a certain intracardiac microbubble density so much ultrasonic energy is reflected that too little energy remains in the distal sound beam, and more distant structures are only weakly imaged, or may entirely disappear. Aside from this ultrasonic overload, video-display overload may occur since the gray-scale display range of video equipment is considerably more limited than the range of reflected ultrasonic energies that can be detected at the transducer. Thus, the upper ranges of intensity (bright echoes) are all displayed as a single maximal intensity on the video screen. Overload may have occured during the maximum intensity of our contrast injections. If so, this would preclude obtaining useful information from calculating the area under these curves: the maximum videodensity during "overload" underestimates the concentration of microbubbles in the sample volume. Whether "overload" occurs after many or most peripheral or central injections has not yet been determined, so the clinical importance of this effect has not been established.

\section{CONCLUSIONS}

Videodensity vs time curves can be obtained from two-dimensional echocardiographic recordings during left ventricular injections in most patients. In the absence of valvular regurgitation or shunts, these usually have a mono-exponential decay, as judged by a straight line when log videodensity is plotted against time. These curves may permit quantitation of cardiac output, ejection fraction and intracardiac shunts, though they have important theoretic and practical limitations.

\section{REFERENCES}

Bastiaans, O. L., Roelandt, J., Piérard L. and Meltzer, R. S. (1981) Ejection fraction from contrast echocardiographic videodensity curves (abstract). Clin. Res. 29, $176 \mathrm{~A}$.

Bloomfield, D. A. (1974) Dye Curves: The Theory and Practice of Indicator Dilution. University Park Press, Baltimore.

Bommer, W. J., Neef, J., Neumann, A., Weinert L., Lee, G., Mason, D. T. and DeMaria, A. N. (1978) Indicatordilution curves obtained by photometric analysis of two-dimensional echo-contrast studies (abstract). Am. J. Cardiol. 41, 370.

Bommer, W. J., Lantz, B., Miller, L., Naifeh, J., Riggs, K., Kwan, O. L., Mason, D. T. and DeMaria, A. N (1979) Advances in quantitative contrast echocardiography: recording and calibration of linear time-concentration curves by videodensitometry (abstract) Circulation 60 (part II), II-18.

DeMaria, A. N., Bommer, W. J., George, L., Neumann, A., Weinert, L. and Mason, D. T. (1978) Combined peripheral venous injection and cross-sectional echocardiography in the evaluation of cardiac disease (abstract). Am. J. Cardiol. 41, 370.

DeMaria, A. N., Bommer, W. J., Riggs, K., Dajee, A., Miller, L. and Mason, D. T. (1960) In vivo correlation of cardiac output and densitometric dilution curves obtained by contrast two-dimensional echocardiography (abstract). Circulation 62 (Suppl III), III-101.

Hagler, D. and Tajik, A. (1978) Videodensitometric quantitation of left-to-right shunts with contrast sector echocardiography (abstract). Circulation 58 (Suppl. II), II-70.

Meltzer, R. S., Serruys, P. W., McGhie, J., Verbaan, N. and Roelandt, J. (1980a) Pulmonary wedge injections yielding left-sided echocardiographic contrast. $\mathrm{Br}$. Heart J. 44, 390.

Meltzer R. S., Meltzer, C. and Roelandt, J. (1980b) Sector scanning views in echocardiology: a systematic approach. Eur. Heart J. 1, 397.

Meltzer, R. S., Tickner, E. G., Sahines, T. P. and Popp, R. L. (1980c) The source of ultrasonic contrast effect. $J$. Clin. Ultrasound 8, 121. 